\title{
An Information Theory of Language (Digital Linguistics)
}

\author{
Kumon Tokumaru \\ Digital Linguist, Japan
}

Copyright $\subseteq 2019$ by authors, all rights reserved. Authors agree that this article remains permanently open access under the terms of the Creative Commons Attribution License 4.0 International License

\begin{abstract}
Digital Linguistics (DL) is an interdisciplinary study that identifies human language as a digital evolution of mammal analog vocal sign communications, founded on the vertebrate spinal sign reflex mechanism. The author identifies the birth of linguistic humans at the time of the laryngeal descent, which provided vowel accented syllables containing logical properties of phonemes and morae. A character set and literacy is the second evolution. Written text is long lasting syllables in the brain of literate persons, and a civilization started as a linguistic phenomenon. At the end of their biological life, they can write their accumulated knowledge with a character set, so that subsequent generations can share their thoughts and experiences to develop further. In the 21 st century, text is available in electronic form, which is interactive against keyword searches. It is time for linguistic humans to integrate disciplinary sciences and correct any errors to establish collective human intelligence. Piaget indicated that concepts can be manipulated correctly based on a group theory, which seems to be a base logic for intellectual evolution of linguistic humans as well as a tool for respectful and productive interdisciplinary discussions. [1][2]
\end{abstract}

Keywords Digital Linguistics, Concepts, Group Theory, "1 To All" Logic, Collective Human Intelligence

\section{Introduction: From the Birthplace of Modern Linguistic Human}

The Recent African Single Origin Hypothesis (RASOH) was first proposed by Cann, Stoneking and Wilson, followed by supportive and more precise analysis, and became the global standard in anthropology. [3] However, archaeology and linguistics have not yet combined their hypotheses on the origins of modern humans into RASOH. The author proposes the RASOH for linguistic humans, who obtained logical properties of phonemes with click consonants 72KA (thousand years ago) during the Toba volcanic winter and morae with vowel accented syllables around 66KA with laryngeal descent, the anatomical evolution of linguistic human.

\subsection{Cradles of Early Humankind and Modern Human}

When we think of humans anthropologically, we realize that there exist two different human concepts with different but not-well distinguished properties in different times. Obviously both of them are very ancient: namely the Early Human of 2-3 MA (million years ago) and Modern Human of 75KA. Although 3 MA is 40 times as old as $75 \mathrm{KA}$, they both are anthropologically and archaeologically located in remote antiquity compared to our day-to-day life. If we compare the skull of Taung Child, 3MA and that of an anatomically modern linguistic human with its developed mandible, it might be easier to recognize the time difference.

In fact, professional anthropologists and archaeologists have not yet clearly distinguished these two concepts with a distinctive identification of anatomical and cultural attributes. For example, the UNESCO World Heritage (WH), "the Cradle of Humankind" in Gauteng region in South Africa, consists of several rainfall bored underground caves in dolomite layer, such as Sterkfontein, Swarkrans, Kromdraai, etc., where fossils of Early Humans, Australopithecus africanus were and are being excavated. It is a cold wet place and not habitable, there is no trace of habitation of humankind at all inside the caves. So precisely speaking, these caves were not the cradles for Early Human evolution. They worked as a deposit site thanks to the alkaline dolomite layer for Early Human fossils which fell down into or were thrown into the caves. "Humankind" discovered in these caves are not Modern Linguistic Humans.

The author read "Origin of the Nude - The Survival of the Unfit", written by Dr. Taizo Shima, and became interested in visiting such a cave environment where naked humans lived before building houses. [4] Although the author had read this book several times, which clearly 
stated that nakedness is the phenomenon of $75 \mathrm{KA}$, he tried to visit "the cradle of humankind" to see the living environment of Modern Linguistic Human. The idea of humans had not yet been fully separated into Early Human and Modern Human in his thinking at that time. Fortunately, by arranging an overnight stay inside Sterkfontein cave with a local guide, he learned that the cave was not habitable and changed his destination to the Klasies River Mouth Caves, in Eastern Cape Province of South Africa, where human habitation from 130 KA until $60 \mathrm{KA}$ had been confirmed by archaeologists. It was astonishing that the existence of oldest modern human site was about 700 miles from Johannesburg. The author had read in a newspaper article in the Guardian, London: Rian Malan's "South African Diary" at the time of the first South African All Race General Elections held in April 1994, and remembered a "riverside cave." With his first visit April 2007, he learned that these caves were located at the river mouth and face the ocean.

\subsection{Klasies River Mouth Caves in South African MSA}

The South African Stone Age is divided into three periods: Early Stone Age (ESA, 2 MA - 200KA), Middle Stone Age (MSA, 300KA - 20KA) and Later Stone Age (LSA, 40KA -).[5] MSA started about 300KA probably with the use of fire for cooking. Hunter-gatherers foraged along the seashore for shells and fish, and probably cooked seafood over fires. As there are a lot of hollowed caves along this coastline, they started to use caves for their homes. Caves in the sea cliff some $20 \mathrm{~m}$ above sea level provided an extremely safe environment against enemies or predators. In such a safe and quiet environment, new born babies could stay in the crib for at least one year without having to fend for themselves; thus, modern humans started to deliver helpless infants.

In South African MSA, Still Bay (SB) and Howiesons Poort (HP) make up two outstanding Neolithic industries. The starting and ending ages for $\mathrm{SB}$ were estimated as 71.9 and $71.0 \mathrm{ka}$ and, for HP $64.8 \mathrm{ka}$ to $59.5 \mathrm{ka}$ [5]. SB and HP emerged along the southern coastline of the African continent. The representative cave for $\mathrm{SB}$ is Blombos Cave, and those for HP are Klasies River Mouth Caves.

Amongst the artefacts unearthed from HP, there were types of tools which were only known from 'advanced' Upper rather than Middle Palaeolithic sites in Europe, and the stratigraphic position (65-59 KA) of Howiesons Poort was highlighted by the excavation of the Klasies River Mouth main site. [6] This time-reversal has not been fully discussed and analyzed, as it requires a Copernican turn from a Eurocentric perspective.

The founding of Still Bay, 71.9 KA, coincides with the Toba volcanic winter. The Still Bay area is on a shallow beach. Klasies River Mouth Caves are located at a few hundred kilometers east of Still Bay, where the waves are high and strong enough to make extremely large caves at the mergence of the Atlantic and Indian Oceans. It is remarkable that the HP artefacts contain engraved ostrich eggshell containers. [7] This sudden augmentation in the precision and sophistication of artefacts at SB/HP indicates that there were critical technological and cultural breakthroughs at the beginning of SB/HP periods, one of which was probably language. This development of Neolithic industries in SB/HP corresponds with a two-stage development of logical properties in voice. By virtue of phonemes to generate an infinite number of word signs and moraic accents to make individual syllables distinguishable in timeline. Owing to accents, word sign and grammatical syllables can be transmitted alternately without any mark, which enabled dualistic grammatical modulation of adjacent word signs.

\subsection{Click Then Syllables Two Stage Evolution of Phonemes}

The archaeological excavation in 1967-68 confirmed that anatomically modern humans had lived inside the caves during the period 120-60 KA. [8] Royer et al. stated that '(T)his study demonstrates that size variation in the Klasies River mandibular and dental samples is greater than in modern human populations, supporting the hypothesis that this Middle Stone Age (MSA) population was more dimorphic.'[9] This dimorphism indicates that the evolution of the mandibular bone should have taken place in KRM to house a descended larynx for vowel resonance.

Deagling found that "no consensus exists that there is a diagnostic anatomical indicator for articulate speech in human evolution" and made extensive analyses to get clearer images of the evolution of the unique mandible of modern human. He concluded that "high-frequency, low-magnitude loads associated with articulate speech are hypothesized to explain the apparent paradox of hypertrophied mandibular bone in contrast to the reduced bone thickness that typifies the remainder of the modern human skull." [10]

It is plausible that the frequent use of the tongue to produce click sounds contributed to the unique mandible of modern humans and provided enough space to house the vocal tract with its descended larynx. Lieberman also suggested that "before the evolution of the modern human SVT (Supra-laryngeal Vocal Tract), the neural substrate that sequences the motor pattern generators that generate speech must have been in place". [11] The production of clicks, followed by the syllable seems appropriate as the neural substrate and a time series evolution.

"Clicks are known as consonants involving a velaric ingressive airstream mechanism, whose geographic and linguistic distribution is restricted to Khoisan and a small number of other languages in Africa." [12] Clicks are the phonemes which can be produced without airflow, i.e. 
before the laryngeal descent and vowels. "Existing analyses of clicks and non-clicks are seldom integrated into a single coherent phonological system...". [13] This incoherency can be evidence for evolution of the clicks-then-syllables time series. Once syllables are obtained, only the Khoisan kept clicks as they were surrounded by a world named by click based words, while those who left Southern Africa abandoned clicks as they had enough phonemes with syllables.

Westphal states that, in "some of the Khoisan languages, most content words begin with clicks, but very few function words do." [14] Content words are concepts such as nouns, verbs and adjectives, and function words are grammatical. He indicated that clicks could not generate grammatical words, probably because they are not moraic. It is plausible that grammatical modulation started with the acquisition of morae, time domain distinctiveness, with vowel accented syllables.

\subsection{Digital Evolution of Intelligence Started in KRM}

The ideas of digital language came from comparisons between modern humans and the Naked-Mole Rat (NMR, Heterocephalus glaber) who live in underground tunnels in the tropical savanna of East Africa. [15] Like modern humans they are also naked with thin skin and thin hair; highly vocal and known for their eusocially structured and altruistic society. But NMRs have just 17 vocal signs in total. This significant difference in vocabulary between modern human and NMR can be explained by the fact that NMRs repeatedly vocalize the same analog sound patterns, whilst the human voice consists of ever changing syllables to transmit sentences. Human language has a vocabulary of more than 100,000 words and can generate as many new word signs as are necessary by permutation of phonemic syllables. From this the author theorized that human language is digital.

Szathmáry and Maynard Smith concluded in "the origins of life": The analogy between the genetic code and human language is remarkable. $\ldots$ in both systems a linear sequence of a small number of kinds of unit can specify an indefinitely large number of outcomes. ... the discrete, digital nature of the units is probably necessary ... It would be interesting to know how far these languages are digital. [16]

Using an internet search engine with "human, digital, language" as keywords, the author discovered a synthesis paper written by a molecular biologist, which introduced the provocative idea of Niels K. Jerne on the immune network mechanism as meaning mechanism and $\mathrm{B}$ lymphocyte as a mobile networking neuron functioning as conceptual device. [17][18][19] These two lectures of Jerne provided DL with the basis to hypothesize a mobile neural network for the mechanism of meaning. [20]

As "ribo-organisms nucleic acids played two roles, as genetic material and enzymes", speech sound played two roles as genetic material conveying collective intelligence and enzymes to generate word memories in the brain of individuals. [21] DL identifies syllables as fundamental logical elements like Ribonucleic acid (RNA) in language to analyze the person-to-person physical layer transmission and the in-brain logical layer linguistic processing. In the evolution of physical layer speech sound stream, vowel accented syllables containing phonemes and morae evolved into character sets for a long time and electronic form with interactive nature. Written text is like DNA, conveying collective human intelligence in a long lasting form. An appropriate part of text should be transcribed into speech form, and interact as enzymes with the brain to construct logical memory networks.

Anatomically there is no unique brain mechanism or organ for modern humans such as a Language Acquisition Device or Linguistic Brain, which are an expression for convenience to keep linguistic processing as mystery. There is no cellular or molecular level hypothesis to explain the so-called Broca and Wernicke areas on the neocortex functioning as a linguistic center. It is highly probable that we use the spinal sign reflex mechanism for word sign processing: the linguistic processing and intelligence are antigen-antibody Neuro-Immune cell network phenomena inside the cerebrospinal fluid (CSF) in the Ventricle System (VS). This is a Tokumaru theory obtained from two Jerne lectures and interdisciplinary research. [20] It is necessary to hypothesize the logical structure and mechanism required to take full benefit of linguistic information in electronic form.

\section{Physical and Logical Digital Evolutions}

\subsection{Inside Ventricle System Immune Cells and Neurons}

In the spinal sign reflex mechanism, the ambient speech sound is represented by 3-dimensional antigen molecular structure inside the brain VS. Table-1 is the result of Network Requirement Analysis for inside VS Immune Cell Networks for the Word Sign Reflex. Antigen terminals of CSF-Contacting Neuron (CSF-CN) and Microglia represent "amplitude envelope fluctuations" of phonemically composed stimuli of individual words. About $90 \%$ of brain cells are immune cells. The grey material which covers the surface of the neocortex is microglia (=macrophages) which present antigen molecules on the surface of the cell membrane. Antibody of B lymphocyte constitutes a specificity pair with the antigen terminal. Word phonetic stimulator $(=\mathrm{CSF}-\mathrm{CN})$ and sensory memories related to that word (=Microglia) are mediated by the mobile neuron (= freely moving B lymphocytes inside CSF) for daily spontaneous concepts. 
Table 1. Network Requirement Analysis for Word Sign Reflex

\begin{tabular}{|c|c|c|c|c|}
\hline Nomenclature & Memory Type & Molecular Structure & Location & Mobility \\
\hline CSF Contacting Neurons & Soundwave & Antigen terminal with cilium & Brainstem Reticular Formation & Fixed \\
\hline $\begin{array}{c}\text { B-lymphocytes } \\
\text { (mobile neurons) }\end{array}$ & $\begin{array}{c}\text { Soundwave } \\
\text { Receptors\& } \\
\text { Networking }\end{array}$ & Antibody $(=3$ antigen CDRs *) & Floating inside CSF & Mobile \\
\hline Microglia & $\begin{array}{c}\text { Soundwave \& } \\
\text { Sensory Memories }\end{array}$ & Antigen terminal & Neocortex & Fixed \\
\hline
\end{tabular}

Inside CSF immune cell networks can serve for word sign reflex. (* CDR: Complementarity Determining Region)

It is a microbiological phenomenon inside the very low noise environment of CSF which is filtrated, purified and regulated by the Choroid Plexus. "CSF is weak alkaline and transparent aqueous solution. This fluid is filtered at choroid plexus and fills the ventricle system, circulates CNS, goes through hindbrain median opening and hindbrain outside ports of the fourth ventricle and arrives at subarachnoid space to be absorbed by vein system." [22] The size of the VS is approximately $150-160 \mathrm{ml}$ and about $500-600 \mathrm{ml} \mathrm{CSF}$ is filtered every day by the Choroid Plexus at each ventricle: CSF changes $3-4$ times every day.

The route of CSF is through the Frontal Lobe, Corpus Callosum, Fornix, Hippocampus, Temporal Lobe, Thalamus, Hypothalamus, Cerebellum, Medulla Oblongata and the Cortex in the Subarachnoid Space. CSF is in contact with almost all parts of the brain, and connects the Limbic System to the Neocortex. This route is the "Information Super Highway" inside the brain, but there is no route map available with a detailed molecular structure of the ventricle wall probably because its importance has not yet been realized. This route demonstrates that lymphocytes floating inside CSF can network with any part of the brain system.

VS of vertebrates started at the so-called Cambrian Explosion 530MA with the coincidental birth of CSF and mobile neurons, designated as B- and T- lymphocytes. $\mathrm{B} / \mathrm{T}$ lymphocytes are categorized as immune cells in contemporary sciences, because scientists had discovered their immune activities before their mobile neural activities. It is plausible that the mobilization of neurons took place inside CSF/VS earlier than immune activities. Mobile neurons were born inside CSF/VS and then expanded their activity area into blood vessels to work as pathogen patrols.

Jerne was the first to point out the close analogy between the immune and the nervous system; immune system, when viewed as a functional network dominated by a mainly suppressive Eigen-behavior, but open to stimuli from the outside, bears a striking resemblance to the nervous system. Both systems display dichotomies and dualisms. The cells of both systems can receive as well as transmit signals. In both systems the signals can be either excitatory or inhibitory.[18] Dichotomy divides the world into two, A or not-A, logic for pattern recognition. Dualism allows one to formulate a logic which connects a signal to an action or receives any arbitrary two signals and produce an output.

\subsection{Establishment of New Sign Reflex Circuit Is Learning}

Sign reflex is a memory based recognition mechanism. It is involuntary, ego-centric and stubborn to serve for fundamental activities such as food, security, reproduction, etc. Its organic, cellular and molecular structures are not yet identified. The author hypothesizes that sign reflex is operated from inside CSF/VS immune cell networks.

Prior to recognition, a memory of word sign and a corresponding memory of meaning must be connected by dualism. Pavlov looked for "the precise conditions under which new conditioned reflexes or new connections of nervous paths are established." [23] In his term, "(previously neutral) conditioned stimulus" is a sound of metronome or bell, and "unconditioned stimulus" is food or poison introduced into the dog's mouth: a first and most essential requisite for the formation of a new conditioned reflex lies in a coincidence in time of the action of any previously neutral stimulus with some definite unconditioned stimulus. Further, it is not enough that there should be overlapping between the two stimuli; it is also equally necessary that the conditioned stimulus should begin to operate before the unconditioned stimulus comes into action. If this order is reversed, the unconditioned stimulus being applied first and the neutral stimulus second, the conditioned reflex cannot be established at all.

It is possible that, when a microglia cell is newly matured in the Hippocampus with the memory of food or poison, an antigen $3 \mathrm{D}$ structure representing a waveform of conditioned stimulus is generated on the cell membrane surface. This is probably true for memorization of a word sign, where a previously unknown word sign is given and followed by a meaningful object.

Immune cells are capable of generating more than $10^{7}$ different types of specificity pairs, which is well beyond the requirements of individual languages. [19]

\subsection{Logic and Mechanism for Grammatical Processing}

On the other hand, there has been not a single hypothesis for the logic and mechanism for grammatical 
processing. The author proposed a "Monaural audition for mother tongue to exploit sound localization function at the brainstem auditory nuclei for the vector analysis of grammatical syllables." [24] This hypothesis was conceptualized by integrating the following interdisciplinary facts:

- Tinbergen demonstrated dichotomic and dualistic behavior patterns of birds to issue danger call against (short neck shadow) + (approaching): sign pattern recognition and movement vector integration [25]

- $\quad$ French langage articulé displays grammatical and word sign syllables vocalized alternately, while Japanese bunsetsu displays word signs then a grammatical syllable dualistic structure. They demonstrate grammatical modulation is made dualistically against adjacent word signs.

- Piraha language without grammatical modulation uses binaural audition for its mother tongue, while other languages use monaural audition for mother tongue.

- In some of the Khoisan languages, function words do not begin with clicks.[14]
- Grammatical syllables are sound symbolic, representing their meanings.

- Antigen terminals of CSF-Contacting Neurons have cilia, motor protein, on top, which can move and indicate directions.[26]

\subsection{Reconfiguration of Brain for Grammar and ...}

When physical evolutions, such as (1) vowel accented syllables, (2) character set and (3) electronic form, take place, the brain benefits from physical improvement such as (1) frequency domain discreteness, (2) long duration and (3) interactive nature. Then, the brain starts to reconfigure its available functions so that other (micro)physical features should also be exploited: (1) time domain discrete sound vector of grammatical syllables, (2) scientific concepts in a very low noise environment and (3) forward error correction by exploiting redundancy and reconfiguring individual logical circuits.(Figure-1, Table-2)

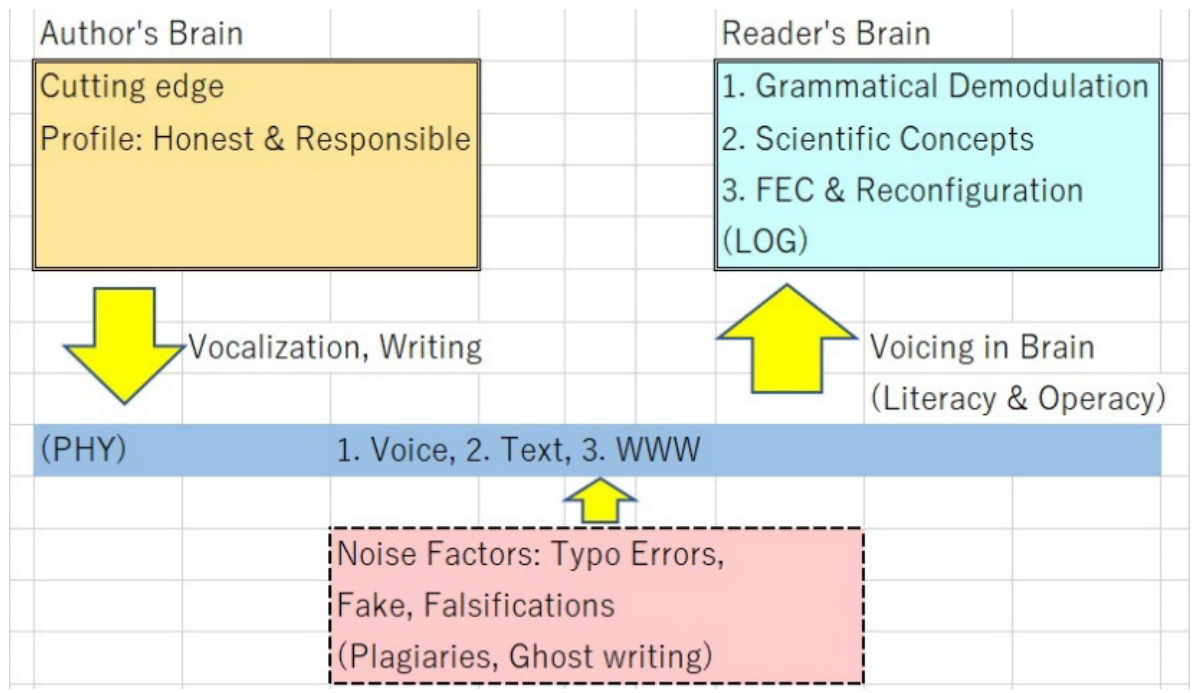

Figure 1. Physical Evolution and Logical Adaptation

Table 2. Digital Evolution in Physical and Logical Layers

\begin{tabular}{|c|c|c|c|}
\hline \multicolumn{2}{|c|}{ Digital Evolution/Adaptation } & \multicolumn{2}{|c|}{ Digital Breakthrough } \\
\hline 1. & Laryngeal Descent: & 1. & lization of Syllables \\
\hline & Sign reflex mechanism & 1) & (PHY) Infinite word signs \\
\hline & Monaural audition of mother tongue & 2) & (LOG) Grammatical demodulation \\
\hline 2. & Character Set \& Literacy & 2. & lasting Syllables \\
\hline & Education \& Publication & 1) & (PHY) Civilization \\
\hline & Low noise asylum & 2) & (LOG) Scientific Concepts \\
\hline 3. & Computer Networks \& Group Theory Operacy* & 3. & active Syllables \& Conceptual Operation \\
\hline & Media Literacy \& Keyword Searches & 1) & $\begin{array}{l}\text { (PHY) Overflow of linguistic information of uncertain } \\
\text { quality }\end{array}$ \\
\hline & $\begin{array}{l}\text { Overcoming sign reflex restrictions, exploiting } \\
\text { redundancy and reconfiguration of consciousness }\end{array}$ & 2) & $\begin{array}{l}\text { (LOG) Forward Error Correction, Interdisciplinary } \\
\text { Integration and Intellectual Genome }\end{array}$ \\
\hline
\end{tabular}

* Operacy is automatic application of group theory to incoming concepts. 
The dualistic integration function of sign reflex corresponded to the dualistic structure of a minimum semantic unit of a word sign and a grammatical syllable. By suspending the binaural audition and sound localization function, the sound waveform of grammatical syllables can be analyzed. The author surmises that the miraculous but invisible mechanism for grammatical processing was obtained by the brain through autopoietic self-reconfiguration in phylogeny and ontogeny.

Written text is a record of the spoken word from times past for literate readers. The knowledge of orthography (i.e. literacy) is a physical layer (= outside brain) mechanism to translate 2-dimensional line drawings (= character set) into inner speech. In a very low noise environment liberated from business and familial duties, monks lived the life of working and studying. The outstanding quality of studies of Dogen (1200-1253), Nicolaus Copernicus (1473-1543), Gregor Johann Mendel (1822-1884), etc. can only be achieved in temples and monasteries.[27][28] A classical index in communication theories, Signal to Noise ratio $(\mathrm{S} / \mathrm{N})$ is obtained signal power divided by noise power. When $\mathrm{N}$ is close to zero, $\mathrm{S} / \mathrm{N}$ is close to infinity. Monks obtained scientific concepts and learned how to operate them.

Linguistic information in electronic form can be stored in a very small memory chip and transmitted to any part of this planet Earth within a second via computer networks. As electronic data is interactive, we can find and obtain relevant documents with keyword searches. Probably we are now at the time to incorporate a group theory (5.3) and reconfigure our brain to take full advantage of electronic linguistic information.

\section{Character Set and True Concept}

\subsection{Civilization Is a Benefit of Long Lasting Syllables}

If the laryngeal descent had taken place $66 \mathrm{KA}$, linguistic humans had spent more than 60 thousand years without any external recording system. Then the first character set, cuneiform, was invented 5KA in Mesopotamia, a very vast flat land, where earth and sand sediment filled the sea between the Eurasia and Gondwana continents. (Figure-2) The size of the land was beyond the perception of humans and some form of recording system was needed for taxation purposes. It can be concluded that the character set was not autopoietically invented like grammar. And, it was not the brain mechanism of linguistic humans which required or needed to have an external memory system. It was invented to support the administrative requirements of a dynasty to govern unimaginably vast areas, and only those who had gone through special training could read and write. Probably they had not foreseen that a character set should help develop civilizations.

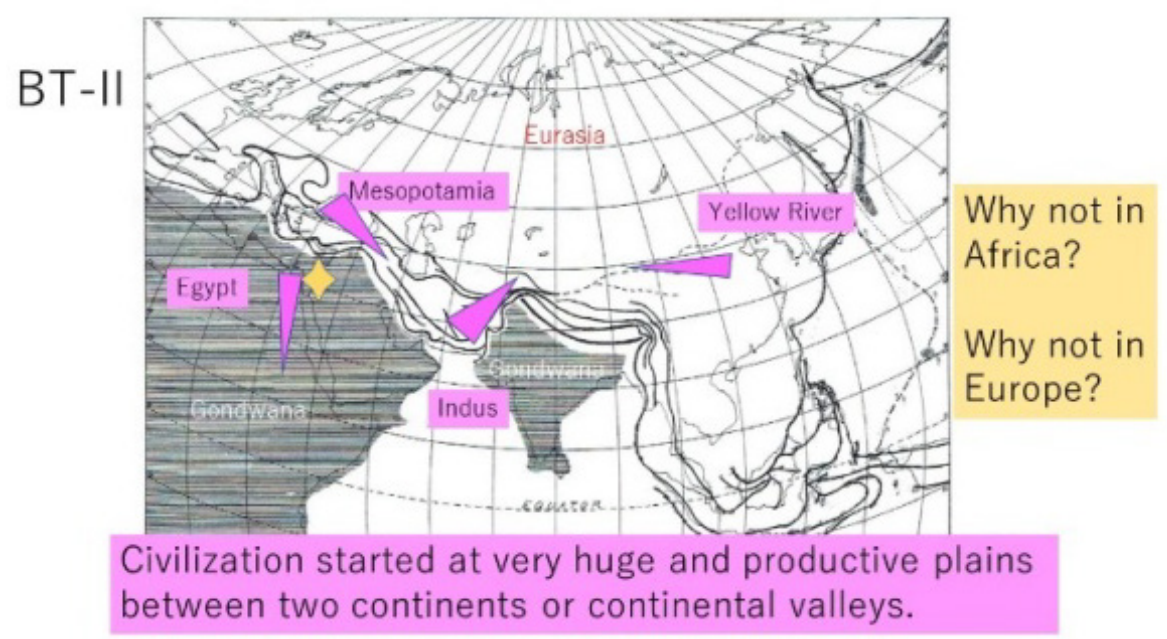

Figure 2. Civilization started at very vast flat land 
A civilization is a linguistic phenomenon of linguistic humans. At the end of their biological life, they can write their accumulated knowledge with a character set, so that subsequent generations can share their thoughts and experiences. This linguistic phenomenon enabled rapid and serial innovations which we call Civilization. The character set and knowledge of orthography provided linguistic humans with an extended external memory system which could be shared and passed on. Civilization can be defined as the "time and space where members can share linguistic information such as law, literature, science, technology, etc. thanks to a character set and literacy, and improve on this through the generations", which is a macroscopic definition. Or, another definition could be "in a civilization, a person is expected to learn what the precedent generations have achieved and go beyond them", a microscopic definition. In our civilizations, modern humans became immortal by inheriting and improving on common intelligence.

Every language has grammar which is to a certain extent similar to that of other languages and so grammar was generated autopoietically. All the linguistic community members can use their mother tongue grammar unconsciously. In the case of characters, there are many languages which don't have a writing system with established and functional orthography. We cannot learn reading and writing without some form of education, which requires discipline and diligence by children. While grammar is natural in its development in any language as well as in the individual, characters are unnatural in their creation and in individual learning. In linguistics, there are many linguists who study grammar, but only a few geniuses such as F. de Saussure discuss characters. [29]

The critical importance of characters, literacy, orthography, education, publications, dictionaries, libraries, social equality, social stability (= peace) in any civilization has been overlooked. Civilization is not industrial or materialistic, but complex linguistic phenomena. Civilization started around $5 \mathrm{KA}$ in vast river valley regions such as the Tigris-Euphrates, Nile, Indus-Ghanga and Yellow River. To date, it has been universally assumed that such civilizations invented their own character sets. But precisely speaking it was opposite: the invention of such characters gave birth to separate civilizations, by enabling the sharing and handing down of knowledge. Thanks to documentation and the dissemination of knowledge through reading, linguistic humans acquired logical immortality in the accumulated knowledge over generations. In this way, civilizations transformed a dugout into a luxury ocean liner and a fire to signal into a communication satellite. This critical function of a writing system in rapid technological innovations has not been fully investigated.

\subsection{Evolution of 1-to-1 into 1-to-all for Conceptual Logic}

At the center of civilization, there is a very low noise environment, such as monasteries, universities and laboratories, where monks and scholars read books and contemplate. "Scientific concepts" can only be obtained in such a quiet environment with dedicated study.

There are not many discussions about complex, abstract or scientific concepts in linguistics. Soviet psychologist Vygotsky made an extensive study on "The Development of Scientific Concepts in Childhood", and identified the intellectual functions required for the acquisition of scientific concepts: a concept is more than the sum of certain associative bonds formed by memory, more than a mere mental habit; it is a complex and genuine act of thought that cannot be taught by drilling, but can be accomplished only when the child's mental development itself has reached the requisite level. At any age, a concept embodied in a word represents an act of generalization. But word meanings evolve. When a new word has been learned by the child, its development is barely starting; the word at first is a generalization of the most primitive type; as the child's intellect develops, it is replaced by generalization of a higher and higher type $-a$ process that leads in the end to the formation of true concepts. ....". [30]

The author believes that any scientific or abstract concepts which are not connected to our five sensory memories must be defined in order to avoid unnecessary confusion. Definition is a logical formula to give generalized meanings to concepts. The author confesses that he had not differentiated "concept" and "word sign" until recently, but now proposes to define very rigorously this applied logic as follows.

"Word sign" is "an in-brain cellular device equipped with a word sign sound receptor, networking with sensory and other word memories with a logic of 1-to-1". When a word sign is connected to multiple memories obtained by multiple experiences, they are recalled one by one and aren't perceived to form a group.

"Concept" is "a matured and developed word sign device to represent all elements in a group based on 1-to-all logic”. It is established through deliberate and thorough thought operations by individual persons. By confirming with no exceptions, the dualistic logic of 1-to-1 evolves into 1-to-all. Concept is a product of intensive thought operations. Only those who keep intellectual curiosity, an enthusiastic desire to learn and strictness in wording can obtain concept. Concepts are axiomatic and can be put into further thought operation and axiomatic investigation. 


\section{Forward Error Correction}

\subsection{Electronic and Interactive Syllables}

Szathmáry and Maynard Smith predicted, "The last transition, through which we are living today, is the use of electric means for storing and transmitting information. We think that the effects of this will be as profound as were those after the origin of the genetic code, or of language."[16] In the 21st century, much linguistic information is available in interactive electronic form. If we put some keywords into Google or other search engines, within seconds they list the relevant linguistic information, which can be immediately accessed, downloaded or converted into speech voice. The Open Public Access Catalog (OPAC) of libraries indicates which libraries hold the books we need (even down to the exact shelf location) and we can find new and secondhand books on the web to be paid with by credit card.

A lot of copyright free books, scientific papers and useful linguistic information provided by public organizations as well as private companies and individuals can be downloaded as PDF files free of charge. We can access them with our smartphone or laptops from anywhere in the world. It is necessary to establish methods to cope with a flood of information of an uncertain quality and reliability, and let it yield profound effects.

\subsection{Forward Error Correction of Linguistic Information}

Forward Error Correction (FEC) is a technology in digital communications to correct errors by exploiting redundancy attached/contained in information without contacting the information sender or original authors.

In information theories, errors are divided into two categories, source coding errors (SCE) for which an author is responsible, and channel coding errors (CCE) for which he is not responsible. As these two consist of an excluded middle, when both SCE and CCE are corrected, we can get error-free information. If one can identify the most advanced, correct and accessible teacher and follow his authentic words, those in later generations can easily go beyond the goal of the teacher, and thus civilization and sciences thrive.

Introduction of FEC into linguistic communication or information is a new initiative. Traditional reading without FEC has a choice of all-or-nothing. They can believe and accept the author, or reject him entirely. With FEC, readers can partly accept a portion and correct the rest by themselves.

\subsection{Channel Coding Error Correction}

At the time of receiving information, receivers should identify a reliable information source, and confirm if it is authentically presented as the original author desired, and if the author is very honest to and responsible for his written words. To become familiar with the author's style, his other books and papers, biography or autobiography, oral history and manuscripts, etc. should also be referred to. Their contemporaries' witness and literature, i.e. autobiography of the author's spouse, oral history of his colleagues, etc., may also provide useful information.

Authors committing plagiarism and using ghostwriters should be regarded as betrayers against truth and their texts must be disregarded, as they are unable to provide any reliable or useful data for productive re-examination.

Posthumous falsification and apocryphal comments are logical and artificial noises, which should be detected and eliminated. As readers in the future have no way to contact authors from the past, there is no active way to differentiate an author's authentic signal from noises. From the readers' side, it is not easy to verify if the words represent the original author's intentions or not. Only printed papers and books published during an author's lifetime with his own proofreading can be supposed to be authentic.

A suspicious example is Plate tectonics (PT), which has no scientific evidence but is now internationally accepted among not only geophysicists but also any scientist and the general public. It has no definition and is not clear who invented this idea, when and how. It was first published in the $3^{\text {rd }}$ Revision of "Principles of Physical Geology" in 1978, 13 years after the death of original author, Arthur Holmes, who had made his second revision just before his demise in 1965 . The revision for the $3^{\text {rd }}$ edition was made by his wife Doris L. Holmes, who was not an author in the first and second edition. Can Arthur be responsible for the $3^{\text {rd }}$ edition?

Redundancy based coding is a fascinating technique for authors to protect their authentic text. The information sender analyzes the data and sends the analysis with data, then the information receiver implements similar analysis to determine if there are any errors occurred during transmission and, when there are any, to correct them based on the logical integrity of the analysis result. This is one of the most important technologies in computer networks to achieve a zero-error requirement.

Dogen applied this coding to his own text. [28] $\mathrm{He}$ assigned serialized numbers for his 75 volume of Shobogenzo with its title, the date and place of lecture delivery and wrote such information at the end of each volume. He also included a number of lectures and his poems in each volume of his analects, Dogen Osho Koroku (Sozanbon), and wrote them as postscripts in the margin of the last page. 20 fake volumes of Shobogenzo were "discovered" posthumously but without authentic postscripts, and another version of analects, Manzanbon, was published about 450 years after the demise of Dogen without postscripts.

Readers with knowledge of such error correction coding can recognize his postscripts as a type of redundancy based coding, and differentiate between 
original and fake texts. When we see any postscript, it is necessary to see if the author needed to protect his text, and if he implied the coding, which was the case of Dogen. Then that postscript should carefully be examined as an error correction code.

Translation errors from the original language into other are channel coding errors, which mislead the true intention of original author. The appropriateness of translation cannot easily be judged. For example, Chomsky translates French "langue" and "langage" both into English "language". Is this good or bad? Why good, why bad?

When channel coding error correction has successfully been done, readers can hear the authentic voice of the author.

\subsection{Source Coding Error Correction}

Reading a book and understanding it is not an easy task, especially if the subject is scientific. In general, authors are much more knowledgeable than their readers. Readers tend to feel that authors are experts, and swallow their words without any evaluation or understanding. It is necessary for readers to demystify authors, treat them as ordinary people and trace their step-by-step learning, thinking and speaking process.

Readers are expected to read the author's text repetitively and intensively so that they can share the prejudice, experiment, experimental results, thoughts, unsolved problems, guess, surprise, etc. of the author. Readers must identify themselves with the author, as Author-Self, and overcome errors in premises, experimental methods, observation and arguments, etc. Readers should verify the reversibility of an author's idea by investigating the authors' deeds and words, back and forward. Without fully understanding the author's knowledge and way of thinking, readers cannot detect the authors' errors and correct them.

Authors are responsible to provide all the necessary information to verify what they claim, and they must be honest and faithful to the facts. Source coding error correction can only be made against the works of honest authors, who respect written text. If only the author is honest, contradictions or inconsistency in the text may have meanings to understand the overall situation better.

Readers must carefully read word by word and between the lines to confirm the author's honesty in his literary style, consistent and careful wording, clear and ambitious purpose, etc. Text written or transmitted by unreliable and dishonest authors should be set aside without reading.

\section{To Reconfigure Logic of Author-Self}

\subsection{Error Correction of Synaptic Connection Hypothesis}

Pavlov experimented with a single sign, or conditioned reflex, to separate from its meaning. For example, he established the Metronome 100 beat/minute as a 'conditioned reflex' for an 'unconditioned reflex' representing food. Then when he gave the same 'conditioned reflex' without 'reinforcement' (= food), the dogs stopped salivating. He named this phenomenon 'internal inhibition' or 'extinction'. [23]

In Lecture-4, he explains as follows: the positive conditioned stimulus itself becomes, under definite conditions, negative or inhibitory; it now evokes in the cells of the cortex a process of inhibition instead of the usual excitation. Conditions favouring the development of conditioned reflexes of the negative or inhibitory type are of frequent occurrence, and these reflexes are met with not less frequently than reflexes of the positive or excitatory type.

The author interprets the above explanation as follows: (1) Pavlov believed that the conditioned reflex is established as a synaptic connection from the sensor area to the motor area of the cortex, and, that, therefore once it is established, the conditioned stimulus should trigger the secretion of saliva regardless of reinforcement (feeding). (2) He interpreted that, when dogs reduced or stopped salivating against a positive conditioned stimulus, the neuron should produce a negative or inhibitory signal instead of an excitatory one. He did not consider that dogs learned the change of sign-meanings through experiences and reconfigured logical connectivity.

He observed that the once established relationship between "conditioned stimuli" and their meanings, food or poison, changed, and he concluded that the conditioned stimulus can change from excitatory to inhibitory and vice versa by 'inhibition': name for convenience based on his assumption, although he could not identify its mechanism. Readers must be aware that 'inhibition' has no further explanation.

In some experiments, he did not change the sign-meaning relationships: Positive Mutual Induction and Differential Inhibition. In Negative Mutual Induction, he tried to change the sign-meaning relationship but he could not. These experiments provide us with interesting insights, although he kept silent on the matter.

Mutual Inductions in Lecture-11 are cyclic experiments using both Excitatory and Inhibitory stimuli for the same meaning (=memory), i.e. food and no food. The Positive Mutual Induction is as follows: when Metronome 100 is the sign for food and Metronome 90 is the no food sign, at first the no food sign is given and no food is provided. Then the food sign is issued, and the dogs salivated without any delay and with 30 to $50 \%$ more than when the sign is used independently.

The Negative Mutual Induction hoped to change the meaning of the Negative sign into a Positive one. Such change of meaning, i.e. from no-food to food, was very easy when the sign was used independently. It was implemented and results were: at first, the food sign is issued, then food is given. Then the no food sign is 
presented and food is provided. Although this cycle of $\{[$ food sign $] \Rightarrow$ food $\Rightarrow$ [no food sign $] \Rightarrow$ food $\}$ was repeated many times, the dogs did not secrete saliva after the no food sign.

Pavlov could not explain the reason for Mutual Inductions. Once a pair of signs for positive and negative meanings is established, they seem to communicate or network each other. This phenomenon was not explained with synaptic connection hypothesis, on which Pavlov was based. This consists of circumstantial evidence for Tokumaru theory that linguistic processing and intelligence are an antigen- antibody Immune cell network phenomena inside CSF in VS.

Another evidence is obtained in his Lectures-1/2 and Lecture-19, which constitute the hypothesis and the experimental results. Pavlov had supposed that conditioned reflexes are established as synaptic connections between sensory and motor areas on the cortex. In Lecture-2 he stated that "(A) decerebrate dog would never have responded by salivary secretion to any stimulus of the kind," and in Lectures 19-21 he removed the sensory areas or cerebral cortex entirely. And his writings in Lecture-19 contradict his statement in
Lecture-2. "The first change which follows the extirpation of some part of the cortex is the almost invariable disappearance of conditioned reflexes; ... no disappearance of the natural conditioned reflexes could be observed even though tested immediately after the recovery from the anaesthetic administered during the operation. ... As a rule the conditioned reflexes disappear after the operation, whether it is performed on one or both of the hemispheres and on whatever portion of them it is carried out. The absence of "artificial" reflexes persists for different lengths of time, varying from a single day to several months." (Lecture-19)

The author presumed that Pavlov should have realized the contradiction and thus he placed the experimental results some distance from the premise. Probably he did not want to take the responsibility to correct the error in his premise, and honestly confessed in Lecture-22: "Indeed I have no doubt that the presentation of the subject- matter attempted in these lectures will in the future still be corrected in many details."

It is not easy to notice the above contradiction. But once we noticed it, we have to reconfigure our consciousness with the necessary error correction.
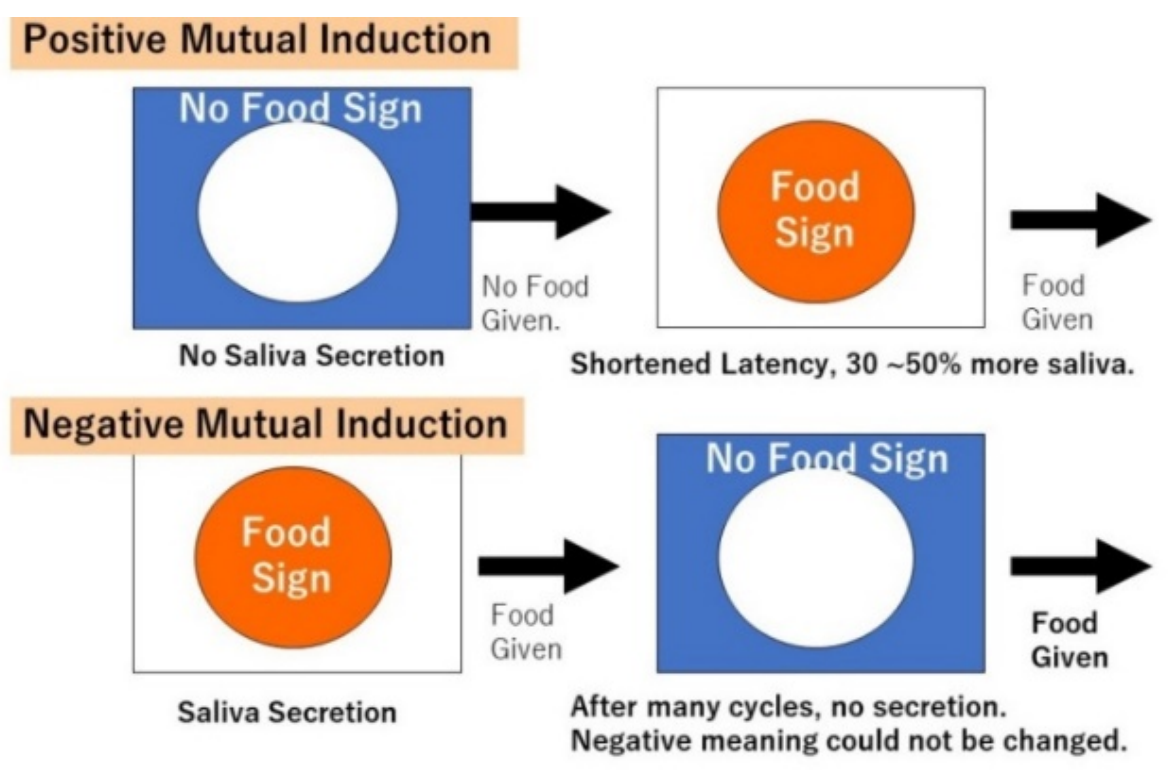

Figure 3. Mutual Induction 


\subsection{Egocentric Nature of Sign Reflex Mechanism}

Piaget pointed out that our intelligence is ego-centric, stable and absorptive. Once it reaches the stage of equilibrium, it easily assimilates a few exceptions. "The remarkable fact in the continuous assimilation of reality to intelligence is, in fact, the equilibrium of the assimilatory frameworks constituted by grouping. ..... Throughout its formation, thought is in disequilibrium or in a state of unstable equilibrium; every new acquisition modifies previous ideas or risks involving a contradiction. From the operational level, on the other hand, the gradually constructed frameworks, classificatory and serial and spatial, temporal, etc., come to incorporate new elements smoothly; the particular section to be found, to be completed, or to be made up from various sources, does not threaten the coherence of the whole but harmonises with it." [1] This equilibrium, which is not desirable for the development of human intelligence, seems to be a trace of the vertebrate spinal sign reflex.

We determine what is right or wrong based on what we already know. We don't have self-diagnosis or reconfiguring mechanisms for our consciousness. It is an egocentric mechanism, which prioritizes a quick response rather than the right answer. Sign reflex is a memory based, passive, self-sufficient mechanism, and not opens to new stimuli. We misshear words we don't know, regardless of their importance. We should pay attention to all words and spot which are new to us or which are used in unfamiliar context. It is envisaged that we have to keep being curious against what we don't know and always be open to and take time in new situations.

Zen and contemporary art have been struggling to overcome the restrictions of reflex. Zen quest for meditation, koan, refuses any commonsense answer. Nonsense objet (not pièce) in contemporary art are presenting opportunities to open our eyes to a new world: we stop reflexes, just gaze at an objet liberated from prejudice and try to be acquainted with its world. To cope with a new word and new meaning, we had better follow the way which koan of Zen and contemporary art are presented.

\subsection{Group Theory Logic for Correct Conceptual Meanings}

Piaget said, "Logic is the mirror of thought, and not vice versa."[1] The dynamic level of human intelligence depends on the in-brain logical circuit for conceptual sign processing. And as we are born innocent or "tabula rasa", we need to construct this logic for linguistic processing postnatally as efficient and as precise as possible.

Logic applied for sign reflex is dualism of 1-to-1 connectivity: (i) action, reminiscence: if $\mathrm{A}$ then $\mathrm{B}$, (ii) comparison: $\mathrm{A}+\mathrm{B}=\mathrm{O}, \times, \triangle, \bigcirc, \equiv, \neq,<$, etc. Linguistic humans with phonemes can generate a new word to name complex situation: (iii) $\mathrm{A}+\mathrm{B}=\mathrm{C}$ (a new word)

The above dualistic logic cannot satisfy the requirement for complex concept, where logic of 1-to-all governs. As 1-to-all logic is not natural, we have to invent and use a special logical circuit to operate concepts and verify the correctness of conceptual meanings.

Piaget displayed five operations to interpolate between psychology and axiomatic logic, 'psycho-logic' or 'logico-psychology' in accordance with the group theory in mathematics. It is plausible that, by applying these formulae as our logic to cope with conceptual operations, we can rectify conceptual meanings. The author tries to explain how to use each operation in the following. [2]

I Composition (Combinativity): $\mathrm{x}+\mathrm{x}^{1}=\mathrm{y} ; \mathrm{y}+\mathrm{y}^{1}=\mathrm{z}$; etc. (Where $x^{*} x^{1}=0 ; y * y^{1}=0$; etc.)

II Inversion (Reversibility): - $\mathrm{x}-\mathrm{x}^{1}=-\mathrm{y}$; etc., from which $\mathrm{y}-\mathrm{x}=\mathrm{x}^{1}$ or $\mathrm{y}-\mathrm{x}^{1}=\mathrm{x}$.

III Associativity: $\left(x+x^{1}\right)+y^{1}=x+\left(x^{1}+y^{1}\right)=(z)$.

IV Identity (General operation of identity): $x-x=0$; $y$ $-\mathrm{y}=0$; etc.

$\mathrm{V}$ Tautology (or special identities): $\mathrm{x}+\mathrm{x}=\mathrm{x} ; \mathrm{y}+\mathrm{y}=\mathrm{y}$; etc. from which $\mathrm{x}+\mathrm{y}=\mathrm{y}$

\subsubsection{Composition " $x+x^{1}=y$ " and " $x * x^{1}=0$ "}

The entirety should be divided into two distinctive concepts consisting of an excluded middle so that further conceptual operations should be effective and meaningful. This is the starting point of any concept and conceptualization. Without this rule, discussions should become ambiguous, meaningless and confusing.

Through thorough and repetitive operations, we have to confirm that this rule prevails. If any exception or ambiguity is discovered, we should stop discussion, investigate, verify and modify, as necessary, the names and meanings to make sure that the rules of composition $\left(\mathrm{x}+\mathrm{x}^{1}=\mathrm{y}\right.$ and $\left.\mathrm{x} * \mathrm{x}^{1}=0\right)$ should prevail in all concepts.

5.3.2. Inversion: $-\mathrm{x}-\mathrm{x}^{1}=-\mathrm{y} ; \mathrm{y}-\mathrm{x}=\mathrm{x}^{1}$ or $\mathrm{y}-\mathrm{x}^{1}=\mathrm{x}$

Composition must be decomposed by inverse operation, which excludes sophistry such as syllogism. Any complex concept can be composed and dismantled into lower level simple concepts with multiple operations.

In this way, any complex concepts can be defined as mathematical equations of clear, basic and simple concepts. "Definition" is not paraphrasing, but it must be equivalent logical expression using generic and lower level concepts.

\subsubsection{Associativity $\left(x+x^{1}\right)+y^{1}=x+\left(x^{1}+y^{1}\right)=(z)$}

When a particular concept means different things or phenomena by different scientists, it is necessary to unify the meanings. This associativity can be used in such occasion: Concept $\mathrm{A}+\alpha=$ Concept $\mathrm{B}+\beta=\mathrm{C}$

A controversial example is "syntax" and "grammar". It is undoubtful that "tense", "comparative", "article", "gender", "honorific", etc. are grammar. However, some syntacticians discuss only syntax as grammar, and 
disregard other authentic and traditional grammar.

DL regards the dualistic structure in speech voice as playing a critical role in grammatical modulation and demodulation, where sound symbolic grammatical syllables modulate adjacent word signs. DL defines grammar as "sound symbolic and mono-syllabic addition or modification to modulate semantically or indicate semantic connectivity of adjacent word signs". And this definition does not include word order (or syntax), which does not accompany syllabic modification. DL and syntacticians are in skewed position, and here associativity should be employed to establish a dialogue: in the definition of DL, grammar is a syllabic addition or modulation, which cannot include word order or syntax. What is the definition of grammar by syntactician to include both syntax and traditional grammar?

\subsubsection{Identity $\mathrm{x}-\mathrm{x}=0$}

This identity is a versatile tool, as we need to verify the identity of conceptual meaning in different societies, cultures, persons, timings, etc. Meanings of daily concepts cannot be generalized, as they consist of individual sensory episodic memories. On the other hand, meanings of logical and scientific concepts must be shared and be identical regardless of the user.

In general, a new concept was born to name a newly discovered phenomenon or material. It is useful to know the unique situation where a new concept was invented or conceived by a particular person: what was observed and perceived, when, where, by whom, and why that concept was named as such. It is of no use and very dangerous to seek the meaning by recombining memories which readers already possess.

All concepts are born through generalization, and we take it as granted that they have unified and standard meanings. It is true for some concepts, for example in molecular biology, corresponding uniquely to definite molecular structures. But in other cases, the meanings often vary, and their definitions are not shown. How should be confirm: X (definition by Dr. A) - X (definition by Dr. B) $=0$ (no discrepancy)?

To make conceptual operation meaningful and productive, the definition of a concept must be perfectly identical to the phenomena represented by that concept: $\mathrm{X}$ $($ phenomena, physical $)-X($ definition, logical $)=0$ (zero, no exception). We have to keep the identity between its definitions and its representing phenomena. If any exceptional phenomenon or contradiction in definition is discovered, we should start discussions and make research to remedy it.

In interdisciplinary study, it is necessary to determine the identity of two or more different but similar concepts. Are they completely identical? How are they different? Can we establish an interdisciplinary concept to unify several disciplinary concepts? For example, to what extent is "vocabulary" in linguistics, "word memories" in brain science, and "consciousness" in psychology identical? (A $\pm \alpha=\mathrm{B} \pm \beta=\mathrm{C}$ ) When differentials $(\alpha, \beta)$ can be identified, concepts in different disciplines can be integrated.

Spencer's words, "instinctive reactions are reflexes" $(\mathrm{A}=\mathrm{B})$, can be interpreted as instinctive reactions in animal ecology are based on reflex mechanism in brain science? To make such comparison easy, the author proposes, in biochemistry related sciences, to resort to molecular structure, which can serve as lingua franca for interdisciplinary integration.

It is important to be aware that some unique and critical ideas conceptualized by a scientist should be shared by interdisciplinary scientists as it is (without any translation): examples are thermodynamic "entropy" named by R. Klausius, "australopithecus africanus" named by R. Dart, and "anatomically modern human with laryngeal descent". Although they were conceived in disciplinary sciences, they should be shared by all disciplines.

On the other hand, there are concept-like expressions proposed for convenience to describe unidentified and unexplained mechanisms, such as "inhibition" of Pavlov, "language acquisition device" and "generative grammar" of Chomsky. Such expressions for convenience are ambiguous. They hide inexplicable reality, cannot be defined by lower level concepts, and cannot be translated into molecular level biology or interdisciplinary scientific concepts. They exist just to fill the gap of undiscovered mechanisms, and are to be replaced by sciences.

\subsubsection{Tautology $x+x=x$}

While Identity (5.3.4) focuses on the identity between two concepts, groups or meanings, tautology deals with the identity among elements in a group. For example, dualistic operation of daily concepts can generate concepts of class and relationship, which can be described with this formula: "orange" + "lemon" = "citrus", "son" + "son" = "grandson", "caterpillar" / "butterfly" = "larva".

Tautology is also useful when we think of very complex systems. For example, when "computer networks" + "genetic representation of Eukaryote" + "language" = "digital" (they are all digital systems), we can refer to a textbook of computer networks for insights to clarify linguistic communication and genetic representation. In fact, DL owes a lot to molecular biology and computer networks when it analyzed invisible mechanism of linguistic processing in the brain.

\section{Conclusions: Vicious Circle Mechanism to Self-organize Complex Concept}

\subsection{Base Logic for Concepts and Conceptual Operations}

A Piagetian idea to apply group theory for conceptual 
meanings is fascinating and very attractive. It should be further discussed, investigated, tried and developed. To date, anecdotes and witty stories by people such as Nasreddin Hodja, in Turkey, and Ikkyu-san, Hiko-ichi, Kicchomu-san, etc. in Japan provide children with some idea on the complexity and difficulty of meanings.

Piagetian formulae shall provide linguistic human with the base logic to deal with complex concepts. Without such logical structure prepared in the brain, we cannot use and operate concepts correctly. It is envisaged that linguistic humans should go through education and training to incorporate a group theory in the brain as an author and a reader to establish collective human intelligence.

When concepts satisfy the conditions of group theory, higher complication level concepts attained by conceptual operations should also fulfill the theory.

\subsection{Mechanism to Reproduce Complexity}

There is a very obvious trait, of the "vicious circle" type, in nature, the simplest expression of which is the fact that very complicated organisms can reproduce themselves. We are all inclined to suspect in a vague way the existence of a concept of "complication" ... Organisms reproduce themselves, that is, they produce new organisms with no decrease in complexity. In addition, there are long periods of evolution during which the complexity is even increasing. [31]

The automatic mechanism to reproduce a complex living creature from a mono dimensional sequence of DNA in a fertilized egg has not yet been clarified. There must is a vicious circle type complication and inter-cellular network regulation mechanisms. When we regard written text as DNA and literacy as a transcription mechanism, what kind of arrangement should we prepare for self-reproduction of human intelligence?

The meanings of complex scientific concepts are not easily obtained. We need to evolve several times. "Every new stage in the development of generalization is built on generalizations of the preceding level; the products of the intellectual activity of the earlier phases are not lost. The inner bond between the consecutive phases could not be uncovered in our experiments because the subject had to discard, after each wrong solution, the generalizations he had formed and start all over again. Also, the nature of the experimental objects did not permit their conceptualization in hierarchical terms." [30]

We had better realize that we use the spinal sign reflex mechanism for linguistic processing and intelligence, which is stubborn, ego-centric, single sign based, without self-diagnosis mechanism, ... We have to overcome being vertebrates.

One of the difficulties in our language lies in the fact that we use the same biological mechanism, B-lymphocytes inside CSF, for word signs and different complexity levels of concepts. In our future dictionary, it would be recommended that, in addition to the parts of speech, such as "noun", "adjective", etc., a (maximum) complexity order of these concepts should also be indicated as follows: Noun0, Noun1, Noun2, Noun3, Noun4. (Table 3) [32][33]

It is time to understand the complexity and omni-potency of digital language as well as the biological mechanism of linguistic processing and intelligence. Then modern linguistic humans will become and behave as homo sapiens in true sense. A group theory should consist of base logic for their consciousness towards an interdisciplinary integration of sciences and FEC of collective human intelligence.

Table 3. Complexity Orders (C.O.) of Concepts

\begin{tabular}{|c|c|c|c|c|c|c|}
\hline C.O. & Sign Types & Elements & $\begin{array}{c}\text { Noise Level } \\
\text { Requirements }\end{array}$ & Accuracy & Phylogeny & Ontogegy \\
\hline 0 & $\begin{array}{c}\text { Reflexive Sign, } \\
\text { Proper Name }\end{array}$ & $\begin{array}{c}\text { Action, Particular } \\
\text { memories }\end{array}$ & High & Specific & $66 \mathrm{KA}$ & Child \\
\hline $1^{\text {st }}$ & $\begin{array}{c}\text { Daily Spontaneous } \\
\text { Concept }\end{array}$ & $\begin{array}{c}\text { Generalization of } \\
\text { Sensory memories }\end{array}$ & Ambient & Egocentric & $66 \mathrm{KA}$ & School Boy \\
\hline $2^{\text {nd }}$ & $\begin{array}{c}\text { Primary Logical } \\
\text { Concept }\end{array}$ & $\begin{array}{c}\text { AND, OR operation of } \\
\text { DSC }\end{array}$ & Ambient & Egological & $5 \mathrm{KA}$ & Student \\
\hline $3^{\text {rd }}$ & $\begin{array}{c}\text { Complex Logical } \\
\text { Concept }\end{array}$ & $\begin{array}{c}\text { Generalization of DSC } \\
\& \text { PLC, }\end{array}$ & Low & Discipline & $2 \mathrm{KA}$ & Philosopher \\
\hline $4^{\text {th }}$ & $\begin{array}{c}\text { True Scientific } \\
\text { Concept }\end{array}$ & $\begin{array}{c}\text { Generalization of DSC, } \\
\text { PLC \& CLC }\end{array}$ & Extremely low & Universal & $\begin{array}{c}20^{\text {th }} \\
\text { Century }\end{array}$ & $\begin{array}{c}\text { Axiomatic } \\
\text { Scientist }\end{array}$ \\
\hline
\end{tabular}




\section{Acknowledgements}

This paper is a full paper version of my presentation, "A Group Theory for Conceptual Meanings (Digital Linguistics)", at the $7^{\text {th }}$ workshop on Meaning and Knowledge Representation (7MKR), held at the Institute of Technology, Blanchardstown (ITB), Dublin, on the $8^{\text {th }}$ July 2018. The author is grateful for the organizer and local coordinator.

\section{REFERENCES}

[1] J. Piaget, "Psychology of intelligence", 1947, Armand Colin, Paris

[2] J. Piaget, "Logic and psychology", 1953, Univ. of Manchester

[3] R.L. Cann, M. Stoneking \& A.C. Wilson, Mitochondrial DNA and human evolution, Nature, 325, 31-6, 1987

[4] T. Shima, "Origin of the nude (Hadaka no kigen)" (in Japanese), Kirakusha, Tokyo, 2004

[5] M. Lombard, et al. (2012). South African and Lesotho Stone Age sequence updated (I). South African Archaeological Bulletin 67(195):120-144

[6] S. Wurz, The Hoawiesons Poort Backed Artefacts from Klasies River: An Argument for Symbolic Behaviour, S.A.A.B. 54(1999) :38-50

[7] P-J Texier, et al, "A Howiesons Poort tradition of engraving ostrich eggshell containers dated to 60,000 years ago at Diepkloof Rock Shelter, South Africa", PNAS 61806185,2010

[8] R. Singer, J. Wymer,(1982) The Middle Stone Age at Klasies River Mouth in South Africa, Chicago U.P

[9] D.F. Royer, C.A. Lockwood, J.E. Scott, F.E. Grine, Size Variation in Early Human Mandibles and Molars from Klasies River, South Africa: Comparison with Other Middle and Late Pleistocene Assemblages and with Modern Humans, AM. J. PHYSICAL ANTHROPOLOGY 140:312-323 (2009)

[10] D.J. Deagling,(2012) The Human Mandible and the Origins of Speech, J. of Anthropology 2:1-14

[11] P. Lieberman, (2002) On the Nature and Evolution of the Neural Bases of Human Language, Yearbook of Physical Anthropology 45:36-62

[12] H. Nakagawa,(2007) Integration of the clicks and the non-clicks Area and culture studies / Tokyo Univ. of Foreign Studies 75:87-96

[13] A. Traill,(1997) Linguistic phonetic features for clicks. In R.K. Herbert (ed), African linguistics at the crossroads: papers from Kwaluseni (1st World Congress of African Linguistics, Swaziland, 18-22, July, 1994), pp.99-117

[14] E.O.J. Westphal,(1971) The click languages of Southern and Eastern Africa, in Sebeok, T.A., Current trends in
Linguistics, Vol. 7: Berlin: Mouton

[15] P.W. Sheerman, J.U.M. Jarvis, R.D. Alexander, "The Biology of the Naked Mole-Rat", Princeton Univ. Press, 1991

[16] E. Szathmáry, J. Maynard Smith, The Origin of Life, Oxford Univ. Press, 1999

[17] H. Noll, The Digital Origin of Human Language - a Synthesis, BioEssays 25:489-500, 2003

[18] N.K. Jerne,(1974) Toward a Network Theory of Immune System, Ann Immunol (Paris). 125C(1-2) :373-89

[19] N.K. Jerne,(1984) The Generative Grammar of the Immune System (The Nobel Lecture)

[20] K. Tokumaru A Mobile Hypothesis of Neural Networks for Spinal Reflex and Linguistic Processing (Digital Linguistics), Linguistics and Literature Studies 6(6):267-277, 2018

[21] E. Szathmáry, J. Maynard Smith, "The major evolutionary transitions," Nature, vol.374, pp.227-232, 16 March 1995

[22] T. Tamotsu, E. Kawano, Y. Haida, "Sensory Organ in the Ventricle System: Paraventricular Organ", Comparative Physiological Chemistry, Vol. 23 (2006) pp143-152, (English translation by the author)

[23] I.P. Pavlov, Conditioned Reflexes, translated by G. V. Anrep (1927), Oxford Univ. Press

[24] K. Tokumaru, Digital Linguistics - The Brain Mechanism for Grammatical Processing, 2018 LAMBERT Academic Publishing, Beau Bassin, Mauritius

[25] N. Tinbergen, The Study of Instinct, Oxford, 1951

[26] B. Vígh, et al, The system of cerebrospinal fluid-contacting neurons. Histol Histopathol (2004) 19: $607-628$

[27] K. Tokumaru, Dogen wo Yomitoku (Read and Understand Dogen), 2017 Fuzambo International, Tokyo, Japan

[28] K. Tokumaru, Error Zero Requirement for Incoming Linguistic Information and Postscript Coding by Dogen (1200-1253), Vestnik Kurganskogo Universiteta (The Herald of Kurgan State University) No.2 (49), 2018, pp97-102 dspace.kgsu.ru/xmlui/handle/123456789/5124.

[29] F.de Saussure, Course in General Linguistics, Philosophical Library, New York, 1959

[30] L. Vygotsky, (1934) Thought and Language. Japanese translation by Shibata Y. Tokyo, Meiji Shoin 1956

[31] J. v. Neumann, (1951) The General and Logical Theory of Automata

[32] K. Tokumaru, Vicious Circle Mechanism to Generate Complex Concepts, Cognitive Studies of Language Vol.XXXIV Oct 10-12, 2018, Russian Aca. Sci. pp77-80

[33] K. Tokumaru, Mobile Neural Networking Hypothesis for Complex Concept and Its Logical Structure (Digital Linguistics), Computer Theory and Engineering, 11(3):51-55, 2019 